\title{
Application of Pushover Analysis in Bridge Piers
}

\author{
Fulin Yang ${ }^{1, a}$, Yunlei Zhang ${ }^{2, b}$, Tao Zheng ${ }^{3, c}$ and Bin $\mathrm{Li}^{4, \mathrm{~d}}$
}

${ }^{1}$ Guangdong Nanyue Transportation Investment \& Construction Co. Ltd, Guangzhou, Guangdong, 516000, China

\author{
${ }^{2}$ School of Transportation, Southeast University, Nanjing, Jiangsu, 210096, China \\ ${ }^{3}$ School of Transportation, Southeast University, Nanjing, Jiangsu, 210096, China \\ ${ }^{4}$ Guangdong Nanyue Transportation Investment \& Construction Co. Ltd, Guangzhou, Guangdong, \\ 516000, China

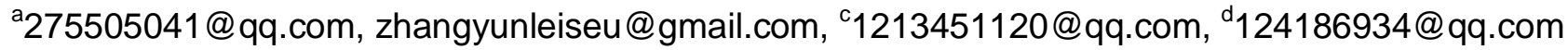

Keywords: pushover analysis; lateral load patterns; performance point; target displacement

Abstract: This paper summarizes basic principles and assumptions of pushover analysis, and then introduces two important factors which may make the results of analysis different: lateral load patterns and calculation of maximum displacement. Subsequently, the paper selects two kinds of lateral load pattern to make pushover analysis of a common single column pier. Then the seismic performance is evaluated based on the performance point. Through comparing the results with those of response spectrum analysis the conclusion is that the results are consistent which illustrates that pushover analysis method is easy, efficient and applicable to the structure.

\section{Introduction}

Pushover analysis is a new method which can be used to evaluate the existing structures and design the new structures. It is a nonlinear static analysis procedure (NSP) essentially. Although it was proposed as early as 1975 , but it was not attracted considerable attention. In the early 90 's, until the performance-based seismic design and the displacement-based seismic design methods were proposed, pushover analysis had its further development [1]. And gradually, it was adopted by seismic design code for some countries and regions, such as United States Technical Committee ATC-40; the national emergency management agency of United States FEMA-356; Europe instruction Eurocode-8; Japan PRESS Guide for design of reinforced concrete structures, and so on.

So far, pushover analysis has many applications in the construction field, but in the bridge field, theoretical research is more than practical application. Pushover analysis to plastic Seismic Response of Bridge was recommended in 2008 "Rules for Seismic Design of Highway Bridges", and 2011 "City Bridges Seismic Design".

\section{Principles and assumptions of pushover analysis}

Pushover analysis is a process that based on the weight of the bear, a structural model presents a certain distribution in a direction along the structural height, and under the action of a lateral load (or lateral displacement) with a gradually increasing trend, internal forces and deformation gradually increases, until control point reaches the target displacement or the structure overturns [2]. Generally, the maximum deformation under the design seismic load is considered as target displacements. This is a combination of static elastic-plastic analysis and response spectrum method, with clear results and abundant information. It was designed to assess the performance of structures under earthquake quickly. Pushover analysis is mainly based on two assumptions [3]:

1) The response of the structure is controlled by the first mode of vibration and mode shape, or by the first few modes of vibration, and that this shape remains constant throughout the elastic and inelastic response of the structure. This provides the basis for transforming a dynamic problem to a static problem which is theoretically flawed. 
2) During each load, deformation of the structures along the height is controlled by a stable shape vector. But in practice, after yielding, the stiffness and shape vector of the structure will change, and it needs more research to confirm whether such changes affect the accuracy of results [4].

\section{Key issues of pushover analysis methods}

The deformation of the structure under lateral force developing from elasticity to plastic can be described with a load-displacement curve (Pushover curve) [5]. As shown in Fig. 1, abscissa represents lateral displacement of structure vertices, and ordinate represents the lateral shear. Each point on the curve represents different performances of structure. The condition of structure and that whether seismic capacity can meet the rule will be decided by location of the pre-set desired performance point.

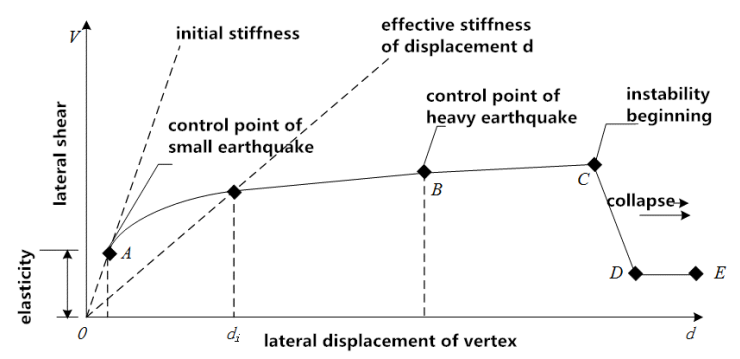

Fig. 1 load-displacement curve

In pushover analysis, there are two key issues that may affect the result: how to choose the right lateral load and how to calculate the target displacement.

Lateral load patterns. In pushover analysis, the lateral load imposed on the structure must reflect the distribution of inertial force of the structure and the changes of structure shape as accurate as possible. Depending on considering the changes of deformation happening after plastic energy state or not, normal load patterns can be divided into: fixed load patterns and adaptive load patterns. Difference between two categories lies mainly in that the adaptive load patterns take into account the structural stiffness change, and they can adjust the load with it.

(1) fixed load patterns

Load distribution in the fixed load patterns will not change with the changes of the structure.

Common fixed load patterns are as follows:

Pattern one: uniform distribution load pattern. As shown in Fig. 2a), lateral force is proportional to quality of node.

Pattern two: inverted triangular distribution load pattern. As shown in Fig. 2b), the load distribution along the height direction is proportional to the quality and height of the node.

Pattern three: parabolic distribution load pattern. As shown in Fig. 2c), loads is proportional to index of height of the node.

Pattern four: basic distribution load pattern. As shown in Fig. 2d), the modal analysis is used to select basic mode along the considered direction, and load is decided by product of basic vibration modes and quality.

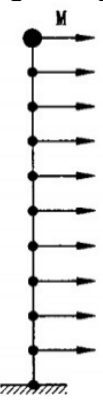

a)uniform distribution

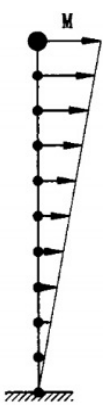

b)inverted triangular distribution 


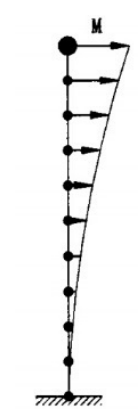

c)parabolic distribution

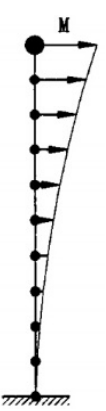

d)basic distribution

Fig. 2 fixed load patterns

(2) adaptive load patterns

Adaptive load patterns require lateral load adjusting constantly based on the development of plastic hinges in the structure during the loading process. This method takes the stiffness change and the diversity of modes into account to modify the lateral loads constantly. In some ways, it can remedy the reasonable basic assumptions of pushover analysis. Modal combination load pattern and equivalent modal distribution pattern are two common patterns of adaptive load distribution (Fig. 3):

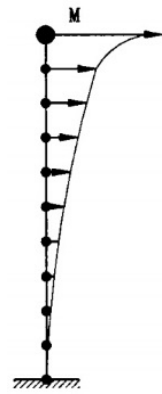

a)modal combination load pattern

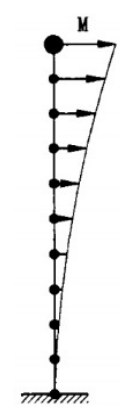

b)equivalent modal distribution pattern

Fig. 3 adaptive load patterns

Target displacement. The target displacement refers to the maximum expected displacement of the nonlinear static analysis of the structure. The displacement of the vertex can response the overall displacement directly and effectively, and correspond to particle displacement of SDOF system. So the vertex of the structure is usually selected as control point, and its displacement is selected as the target displacement ${ }^{[6]}$. Now, there are many methods to calculate the target displacement, such as "capacity spectrum method" adopted by United States Technical Committee ATC-40 and the Japan new building standards law (BSL 2000), "target displacement method" recommended by the national emergency management agency of United States FEMA-356. FEMA-440 improved the two methods mentioned above based on more practical research, and proposed the "equivalent linear" and "influence coefficient method for displacement". This paper just introduces "capacity spectrum method".

Capacity spectrum method essentially puts structural capacity and requirements for structure seismic movements in the same graphic to compare each other and evaluate structural performance during the earthquake visually. Structural capacity is represented by a curve which consists vertex displacement $u_{\mathrm{p}}$ and base shear $V_{b}$, and be obtained by pushover analysis. Then converse the curve to a capacity spectrum curve which consists spectral displacement $S_{d}$ and spectral acceleration $S_{a}$. Conversion formulas are as follows [7]:

$$
\begin{gathered}
S_{a}=\frac{V_{b}}{M_{1}^{*}} \\
S_{d}=\frac{u_{n}}{\Gamma_{1}^{*} \Phi_{N 1}}
\end{gathered}
$$




$$
\begin{aligned}
& M_{1}^{*}=\left(\sum_{j=1}^{N} m_{j} \phi_{j 1}\right)^{2} / \sum_{j=1}^{N} m_{j} \phi_{j 1}^{2} \\
& \Gamma_{1}^{*}=\sum_{j=1}^{N} m_{j} \phi_{j 1} / \sum_{j=1}^{N} m_{j} \phi_{j 1}^{2}
\end{aligned}
$$

Where $M_{1}^{s}$ is the effective mass of the first model, $\Gamma_{1}$ is the participation factor of the first modal, $\phi_{N 1}, \phi_{j 1}$ is the amplitude of the node (vertex control node) and some node in the first mode, $N$ is the total number of the node of bridge pier column, $m_{j}$ is the mass of the node j.

Requirement of seismic structure is converted from the standard response spectrum (period $\mathrm{T}$ as abscissa, spectral acceleration $S_{0}$ as ordinate) into ADRS spectrum (also known as demand spectrum), the conversion formulas are as follows:

$$
S_{d}=\left(\frac{T}{2 \pi}\right)^{2} S_{a}
$$

Place the two curves in the same coordinate system, observe the intersection. If there is no intersection of the curves, it means that the structure needs some modifications to improve its seismic capacity; if the curves have intersection, the intersection will be known as performance point, namely target displacement. Then compare the intersection and allowing criteria to determine whether the structure can meet the seismic requirements.

\section{Example analysis}

Use a single-column pier as example. Pier section is $1.7 \mathrm{mx} 1.4 \mathrm{~m}$ thin-walled rectangles, C40 concrete and B25 longitudinal bars, B16 stirrup, bi-directional 4 limbs, spacing of $10 \mathrm{~cm}$, and bent caps. For easy analysis, the end of pier is consolidated. Load delivered from the superstructure imposes on the coping center in the form of concentrated force. Finite element model is shown in Fig. 4.

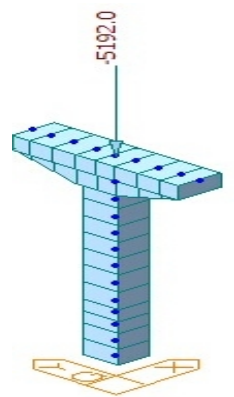

Fig. 4 finite element model of single-column pier

Adopt pattern one and pattern four described above to load structure separately and establish pushover curve. Seismic demand spectrum uses E2 earthquake with fortification intensity 7 and seismic peak acceleration $0.15 \mathrm{~g}$. Fig. 5 and Fig. 6 show the intersection of the capacity spectrum curve and the seismic demand spectrum curve under the two lateral load distribution model, considering both directions along the bridge and cross the bridge, namely performance points.

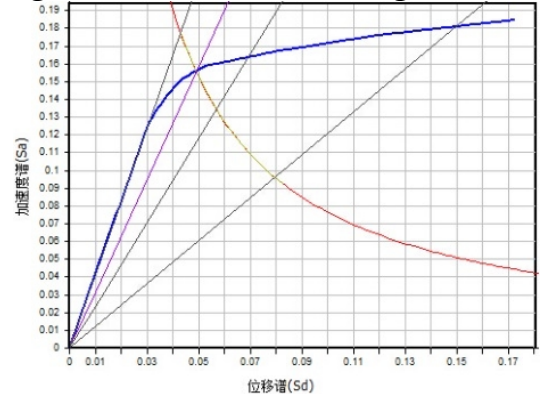

a) uniform distribution

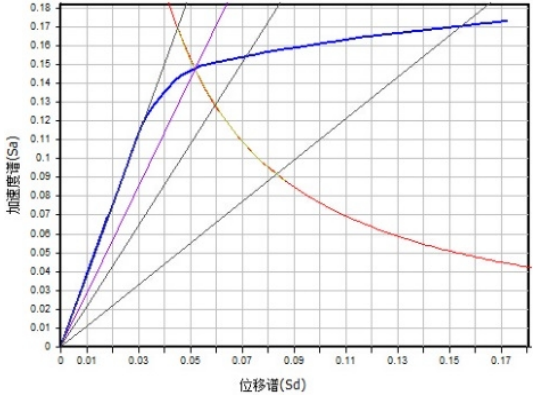

b) basic distribution

Fig. 5 performance points under E2 earthquake along the bridge 


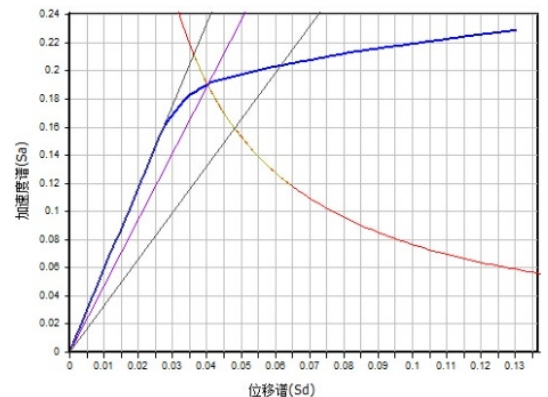

a) uniform distribution

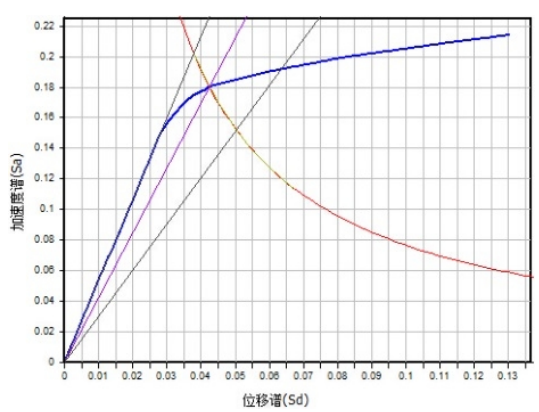

b) basic distribution

Fig. 6 performance points under E2 earthquake cross the bridge

Summarize performance characteristics under E2 earthquake in Table 1 below.

Table 1 summary of performance characteristics under E2 earthquake

\begin{tabular}{|c|c|c|c|c|}
\hline \multirow{2}{*}{ Project } & \multicolumn{2}{|c|}{ Along the bridge } & \multicolumn{2}{c|}{ Cross the bridge } \\
\cline { 2 - 5 } & $\begin{array}{c}\text { Uniform } \\
\text { distribution }\end{array}$ & $\begin{array}{c}\text { Basic } \\
\text { distribution }\end{array}$ & $\begin{array}{c}\text { Uniform } \\
\text { distribution }\end{array}$ & $\begin{array}{c}\text { Basic } \\
\text { distribution }\end{array}$ \\
\hline $\begin{array}{c}\text { Spectral } \\
\text { displacement } \\
\mathrm{S}_{\mathrm{d}}(\mathrm{cm})\end{array}$ & 4.909 & 5.184 & 4.025 & 4.245 \\
\hline $\begin{array}{c}\text { Spectral } \\
\text { acceleration } \mathrm{S}_{\mathrm{a}}(\mathrm{g})\end{array}$ & 0.156 & 0.1477 & 0.1903 & 0.1804 \\
\hline $\begin{array}{c}\text { Base bear } \\
\text { V(kN) }\end{array}$ & 889.8 & 842.7 & 1078 & 1022 \\
\hline $\begin{array}{c}\text { Displacement of } \\
\text { control point D }\end{array}$ & 5.7 & 6.019 & 4.64 & 4.893 \\
\hline
\end{tabular}

As shown in Fig. 5, Fig. 6 and the Table 1, under E2 earthquake, performance points under the two lateral load patterns both along the bridge and cross the bridge, are located within plastic of the spectrum. It means that concrete of component has cracked, and the structure has been in plastic energy dissipation mode. And in this moment, the displacement that has occurred is not so much and the elastic-plastic region after the performance is still abundant. This indicates that the seismic performance of structure can meet the requirements and the structure will still be in good state in the earthquake.

\section{Comparison with the results of response spectrum analysis}

The seismic design of highway bridges rules propose that b class bridges under E1 and E2 earthquake should adopt SM (single modal response spectrum or spectral methods) or MM (multi-mode response spectrum or spectral methods) to make the seismic analysis. Results of response spectrum analysis and pushover analysis are compared.

Under E2 earthquake, structure gets into plastic. Based on the ideal elastic-plastic axial force-bending moment-curvature curves, calculate stiffness reduction coefficient and obtain the base shear force and the displacement of vertex along the bridge and cross the bridge. Results are shown in Table 2. Comparison with the results of pushover analysis is shown in Table 2.

Table 2 results of response spectrum analysis under E2 earthquake

\begin{tabular}{|l|l|c|}
\hline Direction & Base shear $(\mathrm{kN})$ & $\begin{array}{c}\text { Displacement of control } \\
\text { point }(\mathrm{cm})\end{array}$ \\
\hline Along the bridge & 984.9 & 5.484 \\
\hline Across the bridge & 1156.7 & 4.6201 \\
\hline
\end{tabular}

Table 3 comparison between pushover analysis and response spectrum analysis

\begin{tabular}{|c|c|c|c|c|}
\hline \multirow{2}{*}{ Project } & \multicolumn{2}{|c|}{ Along the bridge } & \multicolumn{2}{c|}{ Across the bridge } \\
\cline { 2 - 5 } & $\begin{array}{c}\text { Uniform } \\
\text { distribution }\end{array}$ & $\begin{array}{c}\text { Basic } \\
\text { distribution }\end{array}$ & $\begin{array}{c}\text { Uniform } \\
\text { distribution }\end{array}$ & $\begin{array}{c}\text { Basic } \\
\text { distribution }\end{array}$ \\
\hline Difference & $-9.66 \%$ & $-14.44 \%$ & $-6.8 \%$ & $-11.65 \%$ \\
\hline
\end{tabular}




\begin{tabular}{|l|l|l|l|l|}
\hline of base shear & & & & \\
\hline \multicolumn{1}{|c|}{ Difference } & $3.94 \%$ & $9.76 \%$ & $0.43 \%$ & $5.91 \%$ \\
of \\
$\begin{array}{l}\text { displacement } \\
\text { of control } \\
\text { point }\end{array}$
\end{tabular}

As shown in the Table 2 and Table 3, the results of pushover analysis and the response spectrum analysis are almost similar. Pier shear and the displacement of control point under uniform distribution load are closer to the results of response spectrum analysis compared to the results under basic distribution load. To sum up, pushover analysis can provide a reliable reference to a quick determination of seismic performance of structures.

\section{Conclusion}

For single-column bridge piers, under the action of E2 earthquake, performance points are located within the plastic of spectrum and the structure has entered the plastic energy dissipation stage and elastic-plastic region after the performance point is still redundant, stating that the structure has better seismic performance.

Compare the results of pushover analysis with those of the response spectrum analysis method, and the results are consistent, indicating that pushover analysis method is suitable for this kind of structure, and can quickly confirm the seismic performance of structures with a reliable extent.

In addition, theoretical basis of pushover analysis method is not very strict. The method is based on the basic assumptions. But it does not fit the actual situation that assume the structure into single degree of freedom system, and effects of higher modes of bridge with high piers cannot be ignored. And after yielding, stiffness and shape vectors will change. It needs further study to confirm whether such changes affect the accuracy of results or not.

\section{References}

[1] Chopra A K, Goel R K. A modal pushover analysis procedure for estimating seismic demands for buildings[J]. Earthquake Engineering \& Structural Dynamics. 2002, 31(3): 561-582.

[2] Huang Jie. Bridge Seismic static elastic-plastic analytical method [J]. Journal of Xuzhou Institute of Technology. 2008, 23(4): 19-23.

[3] Huai Huafeng, Zhang Shanyong, Sheng guangzu. Study of high pier of Bridge Seismic demand based on the modal Pushover analysis [J]. Journal of China \& Foreign. 2012, 32(1): 152-159.

[4] Liu Dexu. Application of Pushover seismic analysis method to bridge structure [J]. Theoretical research on urban construction. 2014(20): 828-829.

[5] Shamsabadi A, Rollins K M, Kapuskar M. Nonlinear soil--abutment--bridge structure interaction for seismic performance-based design[J]. Journal of geotechnical and geoenvironmental engineering. 2007, 133(6): 707-720.

[6] Fajfar P. A nonlinear analysis method for performance-based seismic design[J]. Earthquake spectra. 2000, 16(3): 573-592.

[7] Paraskeva T S, Kappos A J, Sextos A G. Extension of modal pushover analysis to seismic assessment of bridges[J]. Earthquake engineering \& structural dynamics. 2006, 35(10): 1269-1293. 